\title{
Medication Adherence to Antihypertensive Triple-Combination Therapy Among Patients Enrolled in a Medicare Advantage Plan
}

\author{
Xin Wang, PhD; Hua Chen, MD, PhD; Ekere Essien, MD, PhD; Jun Wu, PhD; \\ Omar Serna, PharmD, BCACP; Rutugandha Paranjpe, MS; and Susan Abughosh, PhD
}

\begin{abstract}
BACKGROUND: Approximately $32 \%$ (75 million) of adults have hypertension in the United States, leading to 1,100 daily deaths and costing more than $\$ 48$ billion annually in medical expenditures. Approximately $25 \%$ of patients with hypertension require triple combination therapy to reach recommended blood pressure. Currently, only 3 single-pill triple-combination therapies are available in the market for the treatment of hypertension. Medication adherence has become a major concern for the health care system, and nonadherence is associated with higher risks of morbidity and mortality.
\end{abstract}

OBJECTIVE: To compare medication adherence rates among single-pill triple-combination therapy, free triple-combination therapy, and fixeddose dual-combination therapy plus a third agent in hypertensive patients enrolled in a Medicare Advantage prescription drug plan using 2 adherence definitions.

METHODS: A retrospective cohort study was conducted using CignaHealthSpring's medical claims database from January 2014 to December 2016. Antihypertensive combination therapy users were classified into a single-pill triple-combination group, a fixed-dose dual-combination plus a third agent group, and a free triple-combination group. Adherence rates using proportion of days covered (PDC) were calculated for each group within a 1-year follow-up period using 2 definitions: a strict one requiring all antihypertensive agents during follow-up and a more relaxed definition requiring any antihypertensive agent during follow-up. Descriptive statistics were examined, and group differences were assessed using chi-square and analysis of variance. Multivariate logistic regression was conducted to control confounders of adherence using both definitions.

RESULTS: 10,836 triple-combination users were identified. In the multivariate model using the first definition, fixed-dose dual-combination plus a third agent was significantly associated with lower adherence compared with single-pill triple therapy $(\mathrm{OR}=0.177 ; 95 \% \mathrm{Cl}=0.119-0.263 ; P<0.001)$. No significant difference was detected between single-pill triple-combination therapy in comparison with free-combination therapy. In the multivariate model using the second definition, fixed-dose dual-combination plus a third agent and free-combination therapy were significantly associated with better adherence in comparison with single-pill triple combination therapy ( $\mathrm{OR}=3.62,95 \% \mathrm{Cl}=2.59-5.05 ; 0 \mathrm{R}=4.31,95 \% \mathrm{Cl}=2.15-8.64$, respectively). Younger age, female gender, language (Spanish), some comorbidities, and previous hospitalization had a negative effect on adherence.

CONCLUSIONS: Measuring adherence to multiple concurrent regimens is complicated and different adherence definitions can result in significant variations in adherence measures. Future research evaluating clinical outcomes with various definitions is needed.

J Manag Care Spec Pharm. 2019;25(6):678-86

Copyright $\odot 2019$, Academy of Managed Care Pharmacy. All rights reserved.

\section{What is already known about this subject}

Combination therapy in the treatment of hypertension has been shown to help improve blood pressure control and tolerability. Medication nonadherence in hypertension is quite common, ranging from $3 \%$ to $65 \%$ for antihypertensive treatments.

\section{What this study adds}

Different adherence definitions resulted in significant variations in adherence measures for each treatment group.

Group-based trajectory modeling was used to classify patients into different adherence patterns for each treatment group when applying the strict definition.

Younger age; female gender; language (Spanish); some comorbidities (diabetes, depression, coronary artery disease, peripheral vascular disease, chronic obstructive pulmonary disease, hyperlipidemia, and dementia); and previous hospitalization had a negative effect on adherence.

$\mathrm{H}$ ypertension is a medical condition in which blood pressure is persistently elevated in the arteries. ${ }^{1}$ In United States, it was reported that approximately $32 \%$ (75 million) of adults have hypertension, which indicates that there is 1 hypertensive patient among every 3 adults. ${ }^{2}$ More than 1,100 deaths per day and $\$ 48$ billion in direct medical costs annually are attributed to hypertension in the United States. ${ }^{3}$ Hypertension has been shown to be a major risk factor for cardiovascular events and mortality. ${ }^{4}$ Guidelines recommend combination antihypertensive drug therapies as first-line treatment for patients with stage 2 hypertension (systolic blood pressure $\geq 160 \mathrm{~mm} \mathrm{Hg}$ or diastolic blood pressure $\geq 100 \mathrm{~mm}$ $\mathrm{Hg}$ ) and for patients with complicated comorbidities such as heart failure, coronary heart disease, diabetes, and chronic kidney disease..$^{5-7}$

Combination therapy in the treatment of hypertension has been shown to help improve blood pressure control and tolerability. ${ }^{8}$ A meta-analysis of 42 trials published by Wald et al. (2009) reported that combining antihypertensive drugs from 2 different drug classes could lower blood pressure 5 times more than doubling the dose of a single drug class agent. ${ }^{9}$ In addition to synergistic blood pressure lowering, combination therapy requires lower dosages of each individual 
drug agent, resulting in fewer side effects and potentially improving compliance..$^{8,10}$

Currently, 3 single-pill triple-combination therapies are available in the market for the treatment of hypertension that are approved by the U.S. Food and Drug Administration (FDA): Exforge HCT (amlodipine, valsartan, hydrochlorothiazide); Tribenzor (olmesartan medoxomil, amlodipine, hydrochlorothiazide); and Amturnide (aliskiren, amlodipine, hydrochlorothiazide). ${ }^{11}$ Exforge HCT became available as generic in 2014. Studies that compared the therapeutic strategy of single-pill fixed-dose combination (FDC) dual therapies versus free-drug or loose-dose combination therapies have found that FDCs enhanced adherence, improved clinical outcomes, and lowered total medical costs. ${ }^{12,13}$ However, to date, real-world data about single-pill, fixed-dose triple-combination therapy are still lacking due to its unavailability before 2010 in the market and Exforge HCT's availability as a generic since 2014.

Medication adherence, which refers to "whether patients have taken the medications as prescribed," has become a major concern for health care providers, payers, and the whole health care system, since nonadherence has been associated with a higher risk of morbidity and mortality, increased utilization of health care services, and decreased quality of life. . $^{14-18}$ Medication nonadherence in hypertension is quite common, ranging from $3 \%$ to $65 \%$ for antihypertensive treatments. ${ }^{19-21}$

Real-world studies have reported suboptimal blood pressure control among hypertensive patients, which can influence cardiovascular patient outcomes. ${ }^{22}$ Adherence to antihypertensive medications is a crucial factor that will affect the outcome of treating hypertension, and nonadherence, in turn, has a negative effect on lowering blood pressure. ${ }^{23,24}$ It is crucial to provide information regarding the effectiveness and adherence rates of antihypertensive combination therapy in a real-world setting, thereby helping to improve treatment outcomes for hypertensive patients.

Studies have reported that, while measuring concurrent adherence to multiple related medications, the range of adherence varied according to the definition of adherence applied. ${ }^{25,26}$ Choudhry et al. (2009) reported that for patients with multiple medications, a definition calculating adherence for at least 1 medication categorized all patients as mostly adherent, but when calculating adherence for all medication classes, it resulted in only 30\%-40\% being adherent. ${ }^{25} \mathrm{~A}$ similar study on adherence to antihypertensive therapy reported different predictors for different definitions of adherence. ${ }^{27}$ Additionally, while calculating adherence patterns, electronic databases have a limitation whereby they classify patients into groups of adherence based on single indicators such as proportion of days covered (PDC), ignoring in part the dynamic nature of nonadherence over time.

Group-based trajectory models can overcome this limitation by capturing adherence with its dynamic nature. It is an alternative new approach to measure long-term adherence patterns by grouping patients according to their prescription-filling patterns over time. ${ }^{28-31}$ Group-based trajectory modeling summarizes longitudinal adherence and is considered better in comparison with conventional approaches, as it is easier to understand and further depicts medication use in each group. ${ }^{30}$ Despite the benefits demonstrated, the application of trajectory modeling to summarize long-term adherence for different antihypertensive combination therapy strategies is still lacking. ${ }^{30}$

The objective of this study was to provide updated information on the utilization and adherence for single-pill triplecombination therapy compared with other triple-combination therapies using 2 different definitions: a strict one requiring all antihypertensive agents during follow-up and a more relaxed definition requiring any antihypertensive agent during followup. Further predictors of medication adherence were examined. Finally, the variability in resulting adherence across time for each treatment group was demonstrated using trajectory modeling for the strict definition.

\section{Methods}

\section{Study Design, Data Sources, and Data Files}

A retrospective cohort study was conducted using CignaHealthSpring's medical claims database (January 1, 2014-December 31, 2016). The protocol was reviewed and approved by the relevant Committee for the Protection of Human Subjects at the University of Houston.

Several computerized data files including membership file, member summary file, institutional claims file, professional claims file, and pharmacy file were used. Membership and member summary files include demographic detail, severity scores (Centers for Medicare $\&$ Medicaid Services [CMS] risk scores), and cost data of beneficiaries for each year. Institutional claims include information on all inpatient claims. The files contain diagnostic information in the form of International Classification of Diseases, Ninth/Tenth Revision, Clinical Modification (ICD-9/10-CM) codes and procedure information in the form of Current Procedural Terminology (CPT) codes. Pharmacy files containing Part D pharmacy data are provided by a pharmacy benefits manager. The pharmacy records include patient- and drug-identifying information, fill dates, days supply, quantity dispensed, and dosing information for each prescription fill.

\section{Study Population}

The study population consisted of elderly patients with hypertension enrolled in the Medicare prescription drug plan in Texas between January 2014 and December 2016.

Inclusion Criteria. Patients were included in this study if they were (a) elderly patients (aged $\geq 65$ ) with a diagnosis of hypertension identified by ICD-9-CM code 401 or ICD-10-CM code 
I10 for hypertension; (b) receiving at least 2 fills of any type of antihypertensive agents (single-pill monotherapy, single-pill fixed-dose combination therapy, or single-pill triple-combination therapy; class of medications available on request) between July 2014 and December 2015; and (c) continuously enrolled in a Medicare prescription drug plan for 6 months before (baseline period) and at least 1 year after the index date (the index date is defined as the first date of receiving triple-combination therapy).

Exclusion Criteria. Patients were excluded if they disenrolled from the drug plan.

Identification of Subgroups. Enrollees with at least 2 prescription fills of single-pill fixed-dose triple-combination therapy were identified as the single-pill fixed-dose triple-combination user group (subgroup I).

Enrollees with at least 2 prescription fills of single-pill fixeddose dual-combination therapy and single-pill monotherapy from a third antihypertensive drug class and having overlapping prescription claims for fixed-dose dual-therapy and singlepill monotherapy were identified as the fixed-dose dual-combination therapy plus a third agent user group (subgroup II). An overlapping prescription was defined as a pharmacy claim for 1 component before or on the runout date (prescription date plus days supply) of the other components. Further, overlap was defined on the drug class, not specific medications within the drug class.

Enrollees with at least 2 prescription fills of single-pill monotherapy from separate antihypertensive drug classes with overlapping claims for each of the separate drug classes with an overlapping claim defined as a pharmacy claim for 1 of the drugs before or on the runout date of the other drugs were identified as the free-drug, triple-drug antihypertensive combination therapy user group (subgroup III).

\section{Operational Definition of Medication Adherence}

Medication adherence was calculated as the PDC for a filled prescription of antihypertensive agents based on the total number of days covered for filled prescriptions divided by the observation time interval. ${ }^{32}$

$$
\mathrm{PDC}=\frac{\text { Number of days in period covered }}{\text { Number of days in the follow-up period }} \times 100 \%
$$

\section{Outcome Measures}

The dependent variable, PDC, was categorized as adherent versus not by using $80 \%$ as the cutoff created as a categorical variable. ${ }^{33}$ The index date for the single-pill triple-combination user group was defined as the date of the first prescription of single-pill triple-combination therapy. The index date for the fixed-dose dual-combination therapy and free-combination therapy group was defined as the date of initiation of the third drug class (Figure 1).
Two adherence measurement definitions were applied in the study. In the first adherence definition (strict), the PDC with triple therapy was defined as the ratio of the number of days on which all 3 antihypertensive agents were available divided by the 1-year follow-up period ( 365 days since the index date) ${ }^{34}$ In the second adherence definition (relaxed), PDC was defined as the ratio of the number of days with at least 1 drug class available divided by the 1-year follow-up period (365 days since the index date). ${ }^{35}$

The details of the adherence definitions are presented in Figure 2. The first graph shows that in the first adherence measurement definition, the total number of days from B to C (with all 3 drugs available) was used as the numerator while the second graph shows that in the second adherence measurement definition, the total number of days from A to E (with at least 1 drug class available) was used as the numerator.

\section{Conceptual Framework}

Andersen's behavioral model (ABM) was used as the conceptual framework. ${ }^{36}$ This model classifies determinants of an individual's health service utilization into predisposing, enabling, and need characteristics. Predisposing characteristics include age, gender, and language. Enabling characteristics include low-income subsidy (LIS) status. Need characteristics include comorbidities, CMS risk score, previous hospitalizations, and previous antihypertensive drug use. The CMS risk score consists of 189 disease classifications for use in adjusting risk of clinical outcomes in Medicare populations. ${ }^{37,38}$ Comorbidities, previous hospitalizations, and antihypertensive drug use were measured during the baseline period ( 6 months before the index date).

The dependent variable was "adherence or not" using 0.8 as the cutoff. Type of combination therapy (categorized as singlepill triple-combination therapy vs. fixed-dose dual-combination plus a third agent vs. free-combination therapy from 3 drug classes) was the major independent variable. The covariates were conceptualized per the conceptual framework of ABM.

\section{Statistical Analysis}

Descriptive statistics were provided for the patients' demographic factors and other variables. Group differences were assessed using chi-square tests for binary variables and analysis of variance for continuous variables. Adherence rate (PDC) using the first definition was calculated for each subgroup within the 1-year follow-up period. A multivariate logistic regression model was conducted using the first definition to control for potential confounders after assessing interaction.

Trajectory Modeling. In addition, group-based trajectory models were also used to classify patients' adherence during the 1-year follow-up period. Monthly PDC given the first definition was calculated during each of the 12 consecutive 


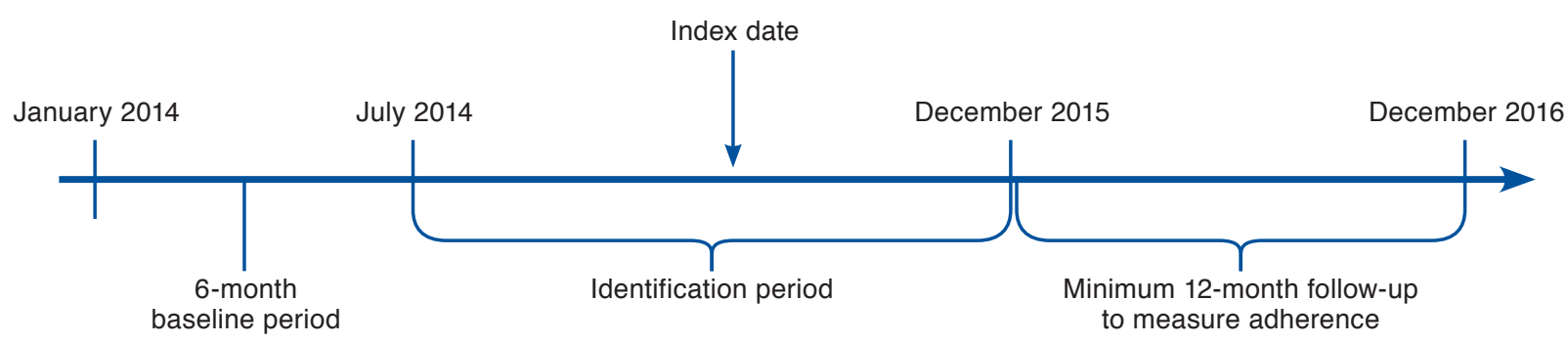

30-day periods separately. A binary indicator for adherence was created for each month, defined as $\mathrm{PDC} \geq 0.8$ (or $\geq 24$ days covered, equivalently). In total, the 12 binary monthly indicators of adherence during each 30-day period as a longitudinal response was created. Trajectory modeling was performed, with the observed adherence pattern, defined by monthly indicators of full adherence (defined as having $>24$ days covered of 30 days), to classify longitudinal adherence pattern for the users in each subgroup. ${ }^{39}$

Sensitivity Analysis. In the sensitivity analysis, we used the second definition to calculate adherence rate for the free triplecombination group. In this approach, we calculated the PDC by using the number of days during which patients had at least 1 of their prescribed medications available during the 1-year follow-up period divided by the total number of days during the follow-up period.

All statistical analyses were performed using the SAS version 9.3 (SAS Institute, Cary, NC) statistical package and a free downloadable add-on package called "Proc Traj," at an a priori significance level of 0.05 .

\section{Results}

In total, 10,836 triple-combination users with diagnosis of hypertension and aged $>65$ years were identified. The singlepill triple-combination user group (subgroup I) consisted of $336(3.10 \%)$ patients with a mean PDC of 0.67 . The fixed-dose dual-combination plus a third agent group consisted of 470 (4.34\%) patients with a mean PDC of 0.37 , and the free triplecombination group consisted of 10,030 (92.56\%) patients with a mean PDC of 0.50 . The adherence rate of single-pill triple-combination therapy group was highest, followed by free-combination therapy group, and the adherence rate of the fixed-dose dual-combination plus a third agent was the lowest. Of the 10,836 patients, 2,845 (26.25\%) were classified as adherent with PDC $\geq 0.8$ and 7,991 (73.74\%) were classified as nonadherent with $\mathrm{PDC}<0.8$. The descriptive baseline sample characteristics of those 10,836 patients, results of t-tests, and chi-square analyses are presented in Table 1 . Results of the interaction assessment showed that there were no significant interactions between the major independent variables and other independent variables at a significance level of 0.05.

\section{First Adherence Definition (Strict)}

Using the "all-3 approach" adherence measurement criteria, results of the logistic regression model are presented in Table 2. Patients on fixed-dose dual-combination therapy along with a third agent were less likely to be adherent compared with those taking single-pill triple combination therapy (odds ratio $[\mathrm{OR}]=0.177 ; 95 \%$ confidence interval $[\mathrm{CI}]=0.119-0.263$ ). Even though the mean PDC of the single-pill triple-therapy group was slightly higher than the free triple-combination group, the results of the multivariate model showed that there was no statistically significant difference in adherence rate between the single-pill triple-combination group and the free-combination group.

Increasing age was associated with better adherence in this population ( $\mathrm{OR}=1.012 ; 95 \% \mathrm{CI}=1.007-1.017)$. Male patients were more likely to be adherent compared with female patients $(\mathrm{OR}=1.293 ; 95 \% \mathrm{CI}=1.173-1.425)$. Those patients who spoke Spanish were less likely to be adherent than those speaking English ( $\mathrm{OR}=0.762 ; 95 \% \mathrm{CI}=0.658-0.882)$. Patients with the following comorbidities were less likely to be adherent compared to those without these comorbidities: diabetes $(\mathrm{OR}=0.597 ; 95 \% \mathrm{CI}=0.518-0.687)$, depression $(\mathrm{OR}=0.432 ; 95 \%$ $\mathrm{CI}=0.308-0.605)$, coronary artery disease $(\mathrm{OR}=0.505 ; 95 \%$ $\mathrm{CI}=0.386-0.660)$, peripheral vascular disease $(\mathrm{OR}=0.573$; 95\% CI $=0.378-0.869$ ), chronic obstructive pulmonary disease (COPD; OR=0.696; 95\% CI=0.552-0.878), hyperlipidemia $(\mathrm{OR}=0.747 ; 95 \% \mathrm{CI}=0.634-0.880)$, and dementia $(\mathrm{OR}=0.368$; $95 \% \mathrm{CI}=0.155-0.874)$. In addition, patients with a previous hospitalization history were less likely to be adherent $(\mathrm{OR}=0.700 ; 95 \% \mathrm{CI}=0.540-0.885)$.

\section{Sensitivity Analysis}

When using the "at least 1" approach (definition 2), we found that the mean PDC for free triple-combination therapy was 0.83 . When using this adherence measurement criterion, the adherence rate for the free-combination group was higher than the adherence rate of the single-pill triple-combination group. 
Definition 1

Days between B and C with all 3 drug classes available $\times 100 \%$

1-year follow-up period

Definition 2

Days between $A$ and $E$ with $\geq 1$ drug class available $\times 100 \%$ 1-year follow-up period

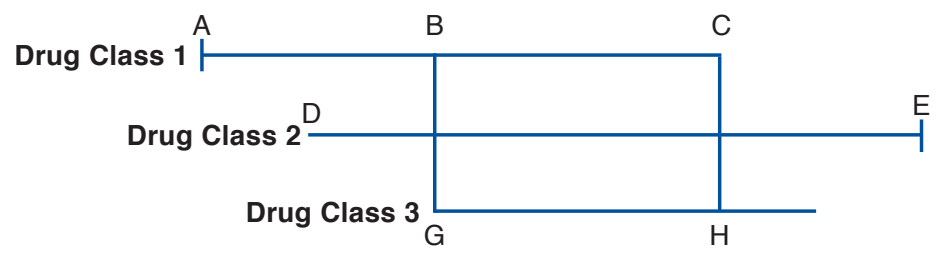

When further using this adherence measurement criteria, results of the logistic regression model (Table 3) examining factors associated with medication adherence revealed that patients on fixed-dose dual-combination therapy along with a third agent were more likely to be adherent compared with those taking single-pill triple-combination therapy $(\mathrm{OR}=3.62$; 95\% CI=2.59-5.05). Also, those taking free-combination therapy were more likely to be adherent compared with those taking single-pill triple-combination therapy $(\mathrm{OR}=4.31 ; 95 \%$ $\mathrm{CI}=2.15-8.64)$.

\section{Trajectory Modeling}

The results of the group-based trajectory modeling for single-pill triple-combination group and free triple-combination group using definition 1 is presented in the Appendix (available in online article). Patients were distributed within 3 groups of increasing adherence: moderate-then-low adherence, high-then-low adherence, and consistently high adherence patterns, respectively. In the single-pill triple-combination group, $20.5 \%, 35.2 \%$, and $44.4 \%$ of patients exhibited moderate-then-low adherence, high-then-low adherence, and consistently high adherence patterns, respectively. In the fixed-dose dual-combination plus a third agent group, 43.6\%, 26.1\%, and $30.3 \%$ of patients had moderate-then-low adherence, highthen-low adherence, and consistently high adherence patterns, respectively. In the free triple-combination therapy group, $33.5 \%, 24.9 \%, 41.7 \%$ of patients exhibited moderate-then-low adherence, high-then-low adherence, and consistently high adherence patterns, respectively.

\section{Discussion}

Findings of this study indicate that there was no statistical difference in the likelihood of being adherent versus not between the single-pill triple-combination group and the free-combination group after adjusting for other confounders in the multivariate regression model using the first adherence measurement definition. Although various previous studies found that increased pill burden was associated with noncompliance, these findings were not consistent with previous literature. ${ }^{40}$ However, some studies also found that pill burden was not a significant predictor of nonadherent behavior. Medication nonadherence is multifactorial, and apart from pill burden, many other factors may also contribute to nonadherent behavior, such as patients' beliefs, disease stage, and physicians' prescribing behavior. ${ }^{41}$ In addition, treatment cost is another factor that may affect adherence, with the cost of free triplecombination therapy being much lower compared with the cost of single-pill therapy. Combinations that are only available as a brand are often more expensive and may, in some cases, lead to a higher copay that may have a negative effect on medication adherence. ${ }^{42,43}$ Thus, the likelihood of adhering to therapy that has a much lower copay may be higher for patients. Although the single-pill triple-combination therapy reduced the pill burden, it was much more expensive than the free triple-combination therapy, which might offset the benefit of reduced pill burden in improving adherence. Both of these factors play an important role in affecting medication adherence.

Results of the multivariate model indicate that patients in the single-pill group were also more likely to be adherent than those taking a fixed-dose dual-combination therapy along with a third agent. Although many antihypertensive regimens are available as generic formulations in the U.S. market, most of the FDCs are only available as brand name drugs. Since dualcombination therapy and single-pill triple-combination are expensive, the reason for better adherence with the single pill here could be due to an increased pill burden associated with the dual-combination therapy plus a third agent treatment group. Future studies can look at the effects of copayment on adherence of antihypertensive combination therapies.

In the sensitivity analysis using the second definition, the adherence rate of the free-combination therapy group was higher compared to the single-pill triple-combination group, 
TABLE 1 Descriptive Statistics of the Baseline Sample Characteristics ( $N=108,036)$

\begin{tabular}{|c|c|c|c|c|c|c|c|c|c|}
\hline \multirow{2}{*}{$\begin{array}{l}\text { Variables } \\
\text { Age, mean }( \pm S D)\end{array}$} & \multicolumn{2}{|c|}{$\begin{array}{c}\text { Total } \\
\mathrm{N}=10,836\end{array}$} & \multicolumn{2}{|c|}{$\begin{array}{l}\text { Single-Pill Triple- } \\
\text { Combination Group } \\
\mathrm{n}=336(3.1 \%)\end{array}$} & \multicolumn{2}{|c|}{$\begin{array}{c}\text { Dual-Combination } \\
\text { + Third Agent Group } \\
\mathrm{n}=470(4.3 \%)\end{array}$} & \multicolumn{2}{|c|}{$\begin{array}{c}\text { Free-Combination } \\
\text { Group } \\
\mathrm{n}=10,030(92.5 \%)\end{array}$} & \multirow{2}{*}{$\frac{P \text { Value }}{0.0086^{\mathrm{a}}}$} \\
\hline & 72.28 & $( \pm 9.48)$ & 70.73 & $(8.49)$ & 72.54 & $(9.01)$ & 72.32 & $(9.53)$ & \\
\hline \multicolumn{9}{|l|}{ Gender, n (\%) } & $<0.0001^{\mathrm{a}}$ \\
\hline Female & 5,000 & $(46.1)$ & 187 & $(55.6)$ & 279 & $(59.3)$ & 4,534 & $(45.2)$ & \\
\hline \multicolumn{9}{|l|}{ Language, $\mathrm{n}(\%)$} & $<0.0001^{\mathrm{a}}$ \\
\hline Spanish & 1,224 & $(11.3)$ & 91 & $(27.0)$ & 108 & $(22.9)$ & 1,025 & $(10.2)$ & \\
\hline CMS risk score, mean $( \pm \mathrm{SD})$ & 1.69 & $( \pm 1.18)$ & 1.26 & $(0.87)$ & 1.52 & $(1.08)$ & 1.71 & (1.19) & $<0.0001^{\mathrm{a}}$ \\
\hline \multicolumn{9}{|l|}{ Health plan, n (\%) } & $<0.0001^{\mathrm{a}}$ \\
\hline LIS & 5,892 & $(54.3)$ & 155 & $(46.1)$ & 197 & $(41.9)$ & 5,540 & $(55.2)$ & \\
\hline Other & 4,944 & $(45.6)$ & 181 & $(53.8)$ & 273 & $(58.0)$ & 4,490 & $(44.7)$ & \\
\hline \multicolumn{10}{|c|}{ Additional risk factors/comorbidities, $\mathrm{n}(\%)$} \\
\hline Previous hospitalization & 6,145 & $(56.7)$ & 2 & $(0.0059)$ & 17 & $(0.03)$ & 1,018 & $(0.1)$ & $<0.0001^{\mathrm{a}}$ \\
\hline Diabetes & 1,944 & $(17.9)$ & 12 & $(0.03)$ & 38 & $(0.08)$ & 1,894 & $(0.1)$ & $<0.0001^{\mathrm{a}}$ \\
\hline Depression & 573 & $(5.2)$ & 0 & $(0.0)$ & 4 & $(0.0085)$ & 569 & $(0.05)$ & $<0.0001^{\mathrm{a}}$ \\
\hline Heart failure & 846 & $(7.8)$ & 0 & $(0.0)$ & 12 & $(0.02)$ & 834 & $(0.08)$ & $<0.0001^{\mathrm{a}}$ \\
\hline End-stage renal disease & 122 & $(1.1)$ & 0 & $(0.0)$ & 3 & $(0.0063)$ & 119 & $(0.01)$ & 0.0758 \\
\hline Myocardial infarction & 92 & $(0.85)$ & 0 & $(0.0)$ & 2 & $(0.0042)$ & 90 & $(0.0089)$ & 0.1252 \\
\hline Coronary artery disease & 695 & $(6.4)$ & 1 & $(0.0029)$ & 13 & $(0.02)$ & 681 & $(0.06)$ & $<0.0001^{\mathrm{a}}$ \\
\hline Peripheral vascular disease & 238 & $(2.2)$ & 4 & $(0.01)$ & 5 & $(0.01)$ & 229 & $(0.02)$ & 0.0935 \\
\hline Cerebrovascular disease & 318 & $(2.9)$ & 1 & $(0.002)$ & 4 & $(0.0085)$ & 313 & $(0.03)$ & 0.0003 \\
\hline Neuropathy & 223 & $(2.0)$ & 1 & $(0.002)$ & 2 & $(0.004)$ & 220 & $(0.02)$ & 0.0021 \\
\hline COPD & 638 & $(5.8)$ & 8 & $(0.02)$ & 10 & $(0.02)$ & 620 & $(0.06)$ & $<0.0001^{\mathrm{a}}$ \\
\hline Retinopathy & 75 & $(0.6)$ & 1 & $(0.002)$ & 3 & $(0.0063)$ & 71 & $(0.007)$ & 0.6647 \\
\hline Obesity & 227 & $(2.0)$ & 0 & $(0.0)$ & 3 & $(0.0063)$ & 224 & $(0.02)$ & 0.0015 \\
\hline Stroke & 320 & $(2.9)$ & 0 & $(0.0)$ & 8 & $(0.01)$ & 312 & $(0.03)$ & 0.0011 \\
\hline Hyperlipidemia & 1,282 & $(11.8)$ & 15 & $(0.04)$ & 26 & $(0.05)$ & 1,241 & $(0.1)$ & $<0.0001^{\mathrm{a}}$ \\
\hline Dementia & 66 & $(0.6)$ & 0 & $(0.0)$ & 1 & $(0.002)$ & 65 & $(0.006)$ & 0.1712 \\
\hline \multicolumn{9}{|c|}{ Previous antihypertensive drug use, $\mathrm{n}(\%)$} & $<0.0001^{\mathrm{a}}$ \\
\hline Monotherapy & 10,093 & $(93.1)$ & 33 & $(0.09)$ & 30 & $(0.06)$ & 10,027 & (99.9) & \\
\hline Dual therapy & 706 & $(6.5)$ & 263 & $(78.2)$ & 440 & $(93.6)$ & 3 & $(0.0002)$ & \\
\hline No treatment & 40 & $(0.3)$ & 40 & $(0.1)$ & 0 & $(0.0)$ & 0 & $(0.0)$ & \\
\hline \multicolumn{10}{|c|}{$\begin{array}{l}\text { Note: Group differences were assessed using chi-square tests for categorical variables and analysis of variance for continuous variables. For counts }<5 \text {, } \\
\text { was applied. } \\
\text { aIndicates statistical significance at a significance level of } 0.05 \text {. } \\
C M S=\text { Centers for Medicare \& Medicaid Services; COPD =chronic obstructive pulmonary disease; LIS=low-income subsidy; SD=standard deviation. }\end{array}$} \\
\hline
\end{tabular}

while in the first definition, no significant difference was detected between single-pill triple-combination therapy in comparison with free-combination therapy. This indicated that there was a large variation in the adherence rate to multiple concurrent regimens when different adherence measurement definitions were applied. ${ }^{35}$ These findings were consistent with previous literature that adopted 3 different adherence measurement approaches and found adherence of multiple medications varied widely using different measurement definitions. ${ }^{35}$ There is no gold standard for measuring adherence of concurrent regimens, and validating different approaches of measuring concurrent adherence to multiple medications is greatly needed. Future research should examine which of these varying adherence definitions is associated with improved clinical outcomes to determine the most ideal definition.
Our study consisted of elderly patients aged $>65$ years, and among them, we found that increased age was significantly associated with higher adherence compared with younger elderly patients. A previous systematic review that analyzed the existing evidence of age as a determinant of medication adherence found that 6 out of 17 studies demonstrated that increased age was positively correlated with higher medication adherence among elderly patients. ${ }^{44}$

We also found that patients with certain comorbidities were less likely to be adherent compared with patients without those comorbidities; for example, depression and dementia were negatively associated with medication adherence in this study. Dementia was negatively associated with medication adherence, possibly because deficits in cognitive function among patients with dementia result in impaired abilities in 


\begin{tabular}{|c|c|c|}
\hline \multirow[t]{2}{*}{ TABLE 2} & $\begin{array}{l}\text { ogistic Regression } \\
\text { ofluential Factors } A \\
\text { ence Using the St }\end{array}$ & $\begin{array}{l}\text { lodel } \\
\text { ociated } \\
\text { t }\end{array}$ \\
\hline & OR $(95 \% \mathrm{CI})$ & $P$ Value \\
\hline \multicolumn{2}{|l|}{ Treatment group } & $<0.0001$ \\
\hline Single-pill group & 1 & \\
\hline $\begin{array}{l}\text { Dual-combination }+ \text { a third } \\
\text { agent group }\end{array}$ & $0.177 \quad(0.119-0.263)$ & \\
\hline Free-combination group & $(0.671-4.948)$ & \\
\hline Age & $1.012 \quad(1.007-1.017)$ & $<0.0001$ \\
\hline \multicolumn{2}{|l|}{ Gender } & $<0.0001$ \\
\hline Female & 1 & \\
\hline Male & $(1.173-1.425)$ & \\
\hline \multicolumn{2}{|l|}{ Language } & 0.0001 \\
\hline English & 1 & \\
\hline Spanish & $(0.658-0.882)$ & \\
\hline CMS risk score & $(0.994-1.076)$ & 0.0926 \\
\hline \multicolumn{2}{|l|}{ Health plan } & 0.4552 \\
\hline LIS & 1 & \\
\hline Other & $(0.943-1.140)$ & \\
\hline Previous hospitalization & $(0.554-0.885)$ & 0.0028 \\
\hline Diabetes & $(0.518-0.687)$ & $<0.0001$ \\
\hline Depression & $(0.308-0.605)$ & $<0.0001$ \\
\hline Heart failure & $(0.610-1.045)$ & 0.1018 \\
\hline End-stage renal disease & $(0.599-1.518)$ & 0.8413 \\
\hline Myocardial infarction & $(0.734-2.299)$ & 0.3699 \\
\hline Coronary artery disease & $(0.386-0.660)$ & $<0.0001$ \\
\hline Peripheral vascular disease & $(0.378-0.869)$ & 0.0088 \\
\hline Neuropathy & $(0.784-1.563)$ & 0.5630 \\
\hline COPD & $(0.552-0.878)$ & 0.0022 \\
\hline Retinopathy & $(0.880-2.650)$ & 0.1321 \\
\hline Obesity & $(0.459-1.018)$ & 0.0612 \\
\hline Stroke & $(0.385-0.785)$ & 0.0010 \\
\hline Hyperlipidemia & $(0.634-0.880)$ & 0.0005 \\
\hline Dementia & $(0.155-0.874)$ & 0.0234 \\
\hline Previous antihypertensive $\mathrm{dr}$ & & 0.1432 \\
\hline No treatment & 1 & \\
\hline Monotherapy & $(0.152-3.346)$ & \\
\hline Dual therapy & $1.762 \quad(0.525-5.916)$ & \\
\hline $\begin{array}{l}\text { Note: Group differences assessec } \\
\text { a Significant results. } \\
\text { CI = confidence interval; COPD } \\
\text { LIS = low-income subsidy; OR = }\end{array}$ & $\begin{array}{l}\text { logistic regression. } \\
\text { cobstructive pulmonary di } \\
\text { to } ; S D=\text { standard deviation }\end{array}$ & \\
\hline
\end{tabular}

planning, executing, and self-management. This might affect patients' ability to adhere to prescribed medications, resulting in medication nonadherence among dementia patients. ${ }^{45}$ The social isolation feelings accompanying depression may reduce cognitive functioning, which can affect patient willingness and motivation to follow a treatment protocol, resulting in lower adherence, as shown in previous literature. ${ }^{46,47}$ Some other comorbidities (e.g., diabetes, hyperlipidemia, COPD, and coronary artery disease) were also found to negatively affect medication adherence. Nonadherence among patients with diabetes and hyperlipidemia is quite common, as these coexisting diseases might cause polypharmacy and side effects are more likely to happen when patients take more medications. ${ }^{48-50}$ In addition, previous hospitalization history was also found to be negatively associated with better adherence, which is consistent with previous findings. ${ }^{51}$

The results of group-based trajectory modeling for each combination therapy group indicate that a relatively larger proportion of patients in the free triple-combination therapy group had a dramatically decreased adherence rate compared to the single-pill triple-combination group using definition 1 . These differences in adherence patterns for each treatment group are not fully depicted when using mean PDC or medication possession ratio values alone. ${ }^{30}$ This finding indicated that the single-pill treatment group had a relatively larger proportion of patients with better adherence in the short-term period compared with other combination groups. The high-then-low adherence group had more variation in adherence over time compared with the consistently high adherence group. Patterns of adherence identified can provide valuable information that can aid in the development of tailored interventions to improve adherence.

\section{Limitations}

This study has some limitations that need to be considered. Since patients were not randomized to the different treatments, we cannot exclude some unmeasured confounding factors that may affect adherence, such as race, marital status, and education level..$^{51,52}$ Some behavioral factors might also influence adherence; for example, a patient's perception and self-management behavior cannot be captured. In addition, pharmacy claims are only an indicator of prescription fills and cannot guarantee that patients actually took the medication, potentially leading to an overestimate of the actual PDC. However, previous literature has shown that prescription refill information recorded in claims data is a relatively accurate measure of overall medication adherence. ${ }^{32,53}$

In addition, there may be some misclassifications when categorizing patients into different combination therapy groups when different measurement criteria for measuring the adherence rate of multiple concurrent regimens were applied. Also, a limitation of claims-based data is the difficulty in capturing whether a physician or patient decided to discontinue or switch a medication. Finally, our study cohort only consisted of elderly patients enrolled in the Cigna-HealthSpring health plan in Texas, so the findings cannot be generalized to the population in other states and to patients in other age groups. 


\section{TABLE 3 Comparison of Logistic Regression Models to Assess Factors Associated with Adherence} Using Different Adherence Measurement Definitions

\begin{tabular}{|c|c|c|c|c|}
\hline & \multicolumn{2}{|c|}{ First Adherence Measurement Definition Model } & \multicolumn{2}{|c|}{ Second Adherence Measurement Definition Model } \\
\hline & OR $(95 \% \mathrm{CI})$ & $P$ Value & OR $(95 \% \mathrm{CI})$ & $P$ Value \\
\hline Treatment group & & $<0.0001^{\mathrm{a}}$ & & $<0.0001^{\mathrm{a}}$ \\
\hline Single-pill group (reference) & 1 & & 1 & \\
\hline Dual-combination + a third agent group & $0.177(0.119-0.263)$ & & $(2.59-5.05)$ & \\
\hline Free-combination group & $1.822(0.671-4.948)$ & & $(2.15-8.64)$ & \\
\hline
\end{tabular}

a significant results.

$C I=$ confidence interval; $O R=$ odds ratio

\section{Conclusions}

Medication adherence is a complex issue affected by various influential factors. The adherence rates of different types of combination therapy varied according to the adherence definition used. Influential factors that significantly affected medication adherence included age, gender, language, some comorbidities, and a previous hospitalization history. The validation of different adherence measurement definitions with clinical outcomes in future research is greatly needed to provide a recommended definition.

\section{Authors}

XIN WANG, PhD; HUA CHEN, MD, PhD; EKERE ESSIEN, MD, PhD; RUTUGANDHA PARANJPE, MS; and SUSAN ABUGHOSH, PhD, Department of Pharmaceutical Health Outcomes and Policy, University of Houston College of Pharmacy, Houston, Texas. JUN WU, PhD, Department of Pharmaceutical and Administrative Sciences, Presbyterian College School of Pharmacy, Clinton, South Carolina, and OMAR SERNA, PharmD, BCACP, CareAllies, a Cigna company, Houston, Texas.

AUTHOR CORRESPONDENCE: Susan Abughosh, PhD, Associate Professor, Department of Pharmaceutical Health Outcomes and Policy, University of Houston College of Pharmacy, 4849 Calhoun Rd., Houston, TX 77204-5047. Tel.: 832.842.8395;

E-mail:smabughosh@uh.edu.

\section{DISCLOSURES}

No outside funding supported this study. Abughosh reports grants from Sanofi, Regeneron, Valeant Pharmaceuticals, BMS/Pfizer, and PhRMA, not related to this study. Serna reports employement with CareAllies, a Cigna company. The other authors have no conflicts of interest to disclose.

\section{REFERENCES}

1. Naish J, Court DS. Medical Sciences. 2nd ed. Philadelphia: Saunders, Ltd.; 2014.

2. Nwankwo T, Yoon SS, Burt V, Gu Q. Hypertension among adults in the United States: National Health and Nutrition Examination Survey, 2011-2012. NCHS Data Brief. 2013(133):1-8.
3. Centers for Disease Control and Prevention. High blood pressure fact sheet. Available at: https://www.cdc.gov/dhdsp/data_statistics/fact_sheets/ fs_bloodpressure.htm. Accessed May 3, 2019.

4. Redon J, Tellez-Plaza M, Orozco-Beltran D, et al. Impact of hypertension on mortality and cardiovascular disease burden in patients with cardiovascular risk factors from a general practice setting: the ESCARVAL-risk study J Hypertens. 2016;34(6):1075-83.

5. James PA, Oparil S, Carter BL, et al. 2014 evidence-based guideline for the management of high blood pressure in adults: report from the panel members appointed to the Eighth Joint National Committee (JNC 8). JAMA. 2014;311(5):507-20

6. American Diabetes Association. Standards of medical care in diabetes J Clin Appl Res Education. 2016;39(Suppl 1):1-112.

7. Ram CV. Fixed-dose triple-combination treatments in the management of hypertension. Manag Care. 2013;22(12):45-55

8. Sood N, Reinhart KM, Baker WL. Combination therapy for the management of hypertension: a review of the evidence. Am J Health Syst Pharm. 2010;67(11):885-94

9. Wald DS, Law M, Morris JK, Bestwick JP, Wald NJ. Combination therapy versus monotherapy in reducing blood pressure: meta-analysis on 11,000 participants from 42 trials. Am J Med. 2009;122(3):290-300.

10. Bangalore S, Kamalakkannan G, Parkar S, Messerli FH. Fixed-dose combinations improve medication compliance: a meta-analysis. Am J Med. 2007;120(8):713-19.

11. Epstein BJ, Shah NK, Borja-Hart NL. Management of hypertension with fixed-dose triple-combination treatments. Ther Adv Cardiovas Dis. 2013;7(5):246-59

12. Brixner DI, Jackson KC 2nd, Sheng X, Nelson RE, Keskinaslan A. Assessment of adherence, persistence, and costs among valsartan and hydrochlorothiazide retrospective cohorts in free-and fixed-dose combinations. Curr Med Res Opin. 2008;24(9):2597-607.

13. Yang W, Chang J, Kahler KH, et al. Evaluation of compliance and health care utilization in patients treated with single pill vs. free combination antihypertensives. Curr Med Res Opin. 2010;26(9):2065-76

14. Ho PM, Bryson CL, Rumsfeld JS. Medication adherence: its importance in cardiovascular outcomes. Circulation. 2009;119(23):3028-35.

15. Deshpande AD, Harris-Hayes M, Schootman M. Epidemiology of diabetes and diabetes-related complications. Phys Ther. 2008;88(11):1254-64.

16. Ho PM, Spertus JA, Masoudi FA, et al. Impact of medication therapy discontinuation on mortality after myocardial infarction. Arch Intern Med. 2006;166(17):1842-47.

17. Rasmussen JN, Chong A, Alter DA. Relationship between adherence to evidence-based pharmacotherapy and long-term mortality after acute myocardial infarction. JAMA. 2007;297(2):177-86. 
18. Loon SC, Jin J, Goh MJ. The relationship between quality of life and adherence to medication in glaucoma patients in Singapore. J Glaucoma. 2015;24(5):e36-e42.

19. Hyre AD, Krousel-Wood MA, Muntner P, Kawasaki L, DeSalvo KB. Prevalence and predictors of poor antihypertensive medication adherence in an urban health clinic setting. J Clin Hypertens. 2007;9(3):179-86.

20. Vrijens B, Vincze G, Kristanto P, Urquhart J, Burnier M. Adherence to prescribed antihypertensive drug treatments: longitudinal study of electronically compiled dosing histories. BMJ. 2008;336(7653):1114-17.

21. Gallagher BD, Muntner P, Moise N, Lin JJ, Kronish IM. Are two commonly used self-report questionnaires useful for identifying antihypertensive medication nonadherence? J Hypertens. 2015;33(5):1108-13.

22. Bakris G, Sarafidis P, Agarwal R, Ruilope L. Review of blood pressure control rates and outcomes. J Am Soc Hypertens. 2014;8(2):127-41.

23. Kamran A, Ahari SS, Biria M, Malpour A, Heydari H. Determinants of patient's adherence to hypertension medications: application of health belief model among rural patients. Ann Medical Health Sci Res. 2014;4(6):922-27.

24. DiMatteo MR, Giordani PJ, Lepper HS, Croghan TW. Patient adherence and medical treatment outcomes: a meta-analysis. Med Care. 2002;40(9):794-811.

25. Choudhry NK, Shrank WH, Levin RL, et al. Measuring concurrent adherence to multiple related medications. Am J Manag Care. 2009; 15(7):457-64.

26. Basak R, McCaffrey Iii DJ, Bentley JP, Przybyla SM, West-Strum D, Banahan BF. Adherence to multiple medications prescribed for a chronic disease: a methodological investigation. J Manag Care Spec Pharm.

2014;20(8):815-23. Available at: https://www.jmcp.org/doi/10.18553/ jmcp.2014.20.8.815.

27. Hedna K, Hakkarainen KM, Gyllensten H, et al. Adherence to antihypertensive therapy and elevated blood pressure: should we consider the use of multiple medications? PLoS One. 2015;10(9):e137451.

28. Nagin D. Group-Based Modeling of Development. Cambridge, MA: Harvard University Press; 2005.

29. Nagin DS. Analyzing developmental trajectories: a semiparametric, group-based approach. Psych Methods. 1999;4(2):139.

30. Franklin JM, Shrank WH, Pakes J, et al. Group-based trajectory models: a new approach to classifying and predicting long-term medication adherence. Med Care. 2013;51(9):789-96.

31. Modi AC, Rausch JR, Glauser TA. Patterns of nonadherence to antiepileptic drug therapy in children with newly diagnosed epilepsy. JAMA. 2011;305(16):1669-76

32. Osterberg L, Blaschke T. Adherence to medication. N Engl J Med. 2005;353(5):487-97.

33. Ho PM, Rumsfeld JS, Masoudi FA, et al. Effect of medication nonadherence on hospitalization and mortality among patients with diabetes mellitus Arch Intern Med. 2006;166(17):1836-1841

34. Leslie SR, Gwadry-Sridhar F, Thiebaud P, Patel BV. Calculating medication compliance, adherence and persistence in administrative pharmacy claims databases. Pharm Programming. 2008;1(1):13-19.

35. Choudhry NK, Shrank WH, Levin RL, et al. Measuring concurrent adherence to multiple related medications. Am J Manag Care. 2009;15(7):457.
36. Babitsch B, Gohl D, von Lengerke T. Re-revisiting Andersen's Behavioral Model of Health Services Use: a systematic review of studies from 1998-2011. GMS Psycho-Social-Med. 2012;9:Docl1

37. Johnson ML, Parikh N, Kunik ME, et al. Antihypertensive drug use and the risk of dementia in patients with diabetes mellitus. Alzheimers Dement. 2012;8(5):437-44

38. Parikh NM, Morgan RO, Kunik ME, et al. Risk factors for dementia in patients over 65 with diabetes. Int J Geriatr Psych. 2011;26(7):749-57.

39. Modi AC, Cassedy AE, Quittner AL, et al. Trajectories of adherence to airway clearance therapy for patients with cystic fibrosis. J Pediatr Psych. 2010;35(9):1028-37

40. Pasina L, Brucato AL, Falcone C, et al. Medication non-adherence among elderly patients newly discharged and receiving polypharmacy. Drugs Aging. 2014;31(4):283-89.

41. Adhikari UR, Taraphder A, Hazra A, Das T. Pill burden does not influence compliance with oral medication in recipients of renal transplant. Indian J Pharmacol. 2016;48(1):21.

42. Gradman AH, Basile JN, Carter BL, Bakris GL; American Society of Hypertension Writing Group. Combination therapy in hypertension. J Am Soc Hypertens. 2010;4(1):42-50.

43. Gibson TB, Ozminkowski RJ, Goetzel RZ. The effects of prescription drug cost sharing: a review of the evidence. Am J Manag Care. 2005;11(11):730-40

44. Krueger K, Botermann L, Schorr SG, Griese-Mammen N, Laufs U, Schulz M. Age-related medication adherence in patients with chronic heart failure: a systematic literature review. Int J Cardiol. 2015;184:728-35.

45. Smith D, Lovell J, Weller C, et al. A systematic review of medication non-adherence in persons with dementia or cognitive impairment. PloS One. 2017;12(2):e0170651.

46. Cukor D, Rosenthal DS, Jindal RM, Brown CD, Kimmel PL. Depression is an important contributor to low medication adherence in hemodialyzed patients and transplant recipients. Kidney Int. 2009;75(11):1223-29.

47. MacLaughlin EJ, Raehl CL, Treadway AK, Sterling TL, Zoller DP, Bond CA. Assessing medication adherence in the elderly: which tools to use in clinical practice? Drugs Aging. 2005;22(3):231-55.

48. van der Wal MH, Jaarsma T, Veldhuisen DJ. Non-compliance in patients with heart failure; how can we manage it? Eur J Heart Fail. 2005;7(1):5-17.

49. van der Wal MH, Jaarsma T. Adherence in heart failure in the elderly: problem and possible solutions. Int J Cardiol. 2008;125(2):203-08.

50. Marcum ZA, Gellad WF. Medication adherence to multi-drug regimens. Clin Geriatr Med. 2012;28(2):287.

51. Marcum ZA, Zheng Y, Perera S, et al. Prevalence and correlates of selfreported medication non-adherence among older adults with coronary heart disease, diabetes mellitus, and/or hypertension. Res Soc Adm Pharm. 2013;9(6):817-27

52. Juarez DT, Williams AE, Chen C, et al. Factors affecting medication adherence trajectories for patients with heart failure. Am J Manag Care. 2015;21(3):e197-e205.

53. MacLaughlin EJ, Raehl CL, Treadway AK, Sterling TL, Zoller DP, Bond CA. Assessing medication adherence in the elderly. Drugs Aging. 2005;22(3):231-55. 


\section{APPENDIX Group-Based Trajectory Model (Using Definition 1)}

\section{A. Single-Pill Group: Adherence vs. Month}

Group 1: Moderatethen-low adherence

Group 2: High-then-low adherence

Group 3: Consistently high adherence

Dotted lines represent confidence intervals

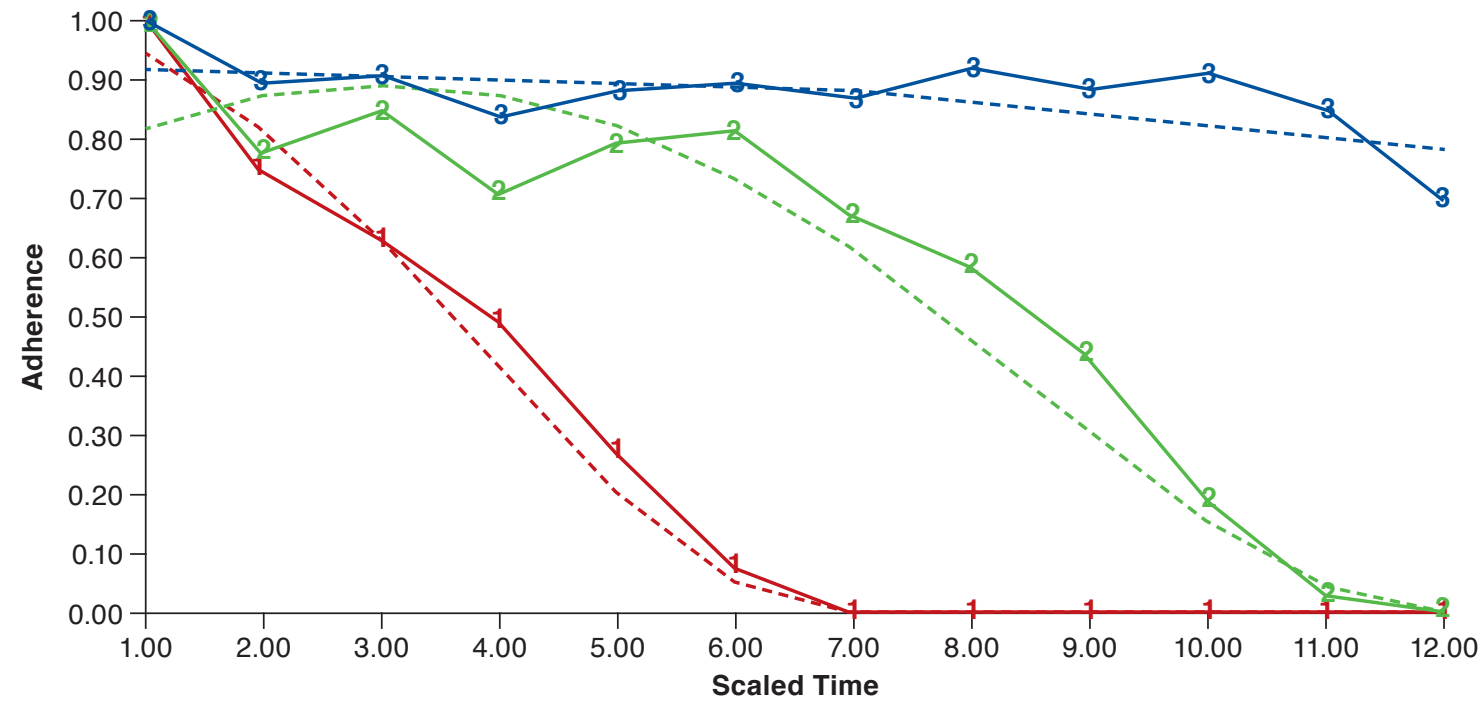

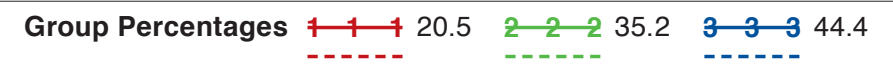

\section{B. Free-Combination Group: Adherence vs. Month}

Group 1: Moderatethen-low adherence

Group 2: High-then-low adherence

Group 3: Consistently high adherence

Dotted lines represent confidence intervals

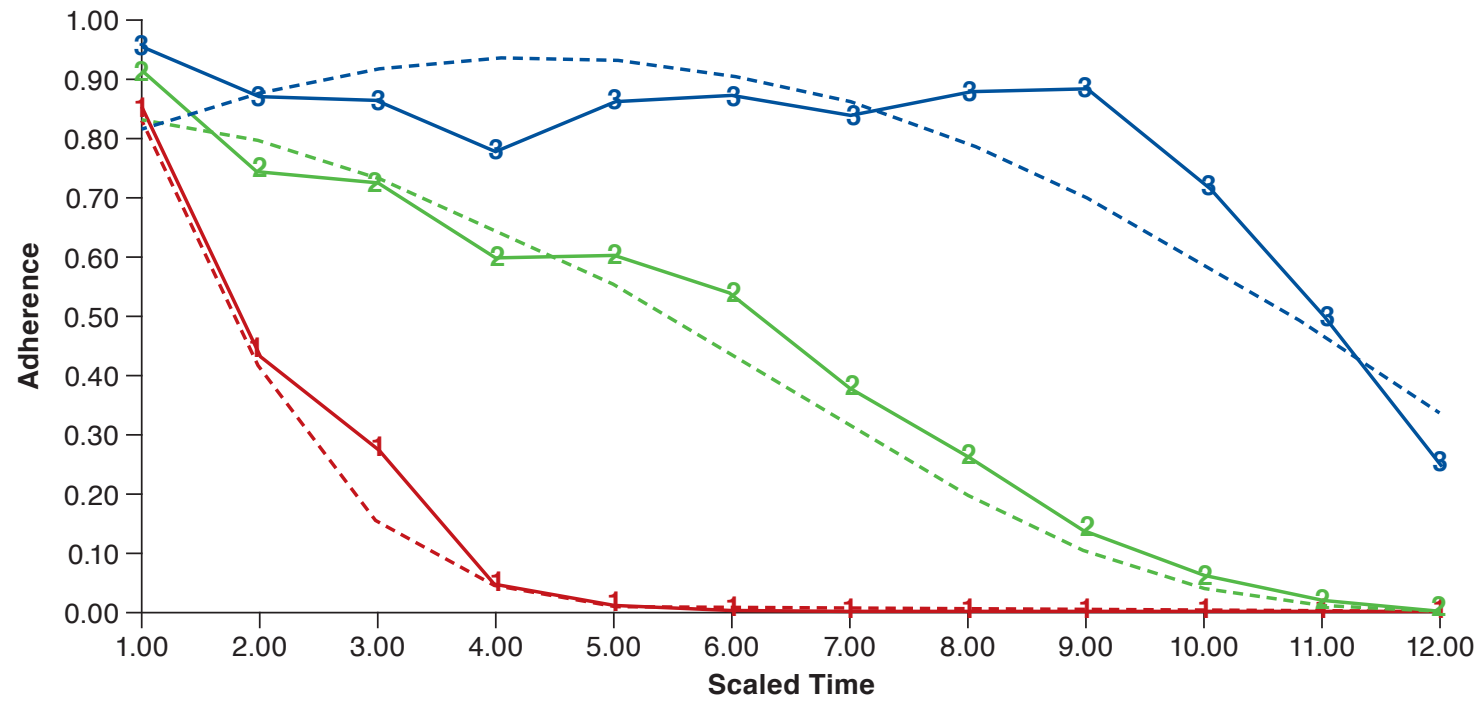

$$
\begin{aligned}
& \text { Group Percentages } \begin{array}{lllllllllll}
1 & 1 & 1 & 33.5 & 2 & 2 & 2 & 24.9 & 3 & 3 & 3
\end{array} 41.7 \\
& \text {--n--- -n---- --n--- }
\end{aligned}
$$

